\title{
Acuut loopoor bij kinderen met trommelvliesbuisjes
}

\author{
Samenvatting \\ Van Dongen TMA, Van der Heijden GJMG, Venekamp RP, Rovers MM, \\ Schilder AGM. Acuut loopoor bij kinderen met trommelvliesbuisjes. Huis- \\ arts Wet 2014;57(9):520-3.
}

ACHTERGROND Het staat niet vast welke behandeling het meest effectief is bij kinderen met trommelvliesbuisjes die een acuut loopoor ontwikkelen: antibiotica(glucocorticoïd)oordruppels, een oraal antibioticum of een afwachtend beleid.

METHODE Een gerandomiseerd pragmatisch interventieonderzoek waaraan in totaal 230 kinderen tussen 1 en 10 jaar oud met trommelvliesbuisjes en een kort bestaand loopoor ( $<7$ dagen) hebben meegedaan. We hebben de kinderen door loting toegewezen aan een van de drie behandelgroepen: hydrocortison-bacitracine-colistineoordruppels (76 kinderen), amoxicilline-clavulaanzuurdrank (77) of een afwachtend beleid (77). De primaire uitkomst was aanwezigheid van otorroe bij otoscopie 2 weken na randomisatie. Secundaire uitkomsten waren onder andere de duur van het initiële loopoor, het totaal aantal dagen met een loopoor en het aantal recidieven na 6 maanden, en complicaties en bijwerkingen van de onderzoeksmedicatie.

RESULtaten Antibiotica-glucocorticoïdoordruppels waren effectiever dan een antibioticumdrank en een afwachtend beleid voor zowel de primaire als secundaire uitkomstmaten. Ten tijde van otoscopie, 2 weken na de start van de behandeling, zagen we dat $5 \%$ van de kinderen die waren behandeld met antibiotica-glucocorticoïdoordruppels nog otorroe had, versus $44 \%$ van de kinderen die een behandeling kregen met een antibioticumdrank (risicoverschil (RV): $-39 \%, 95 \%-\mathrm{BI}:-51 \%$ tot $-26 \%$ ) en $55 \%$ van de kinderen bij wie werd afgewacht (RV: $-49 \%, 95 \%-B I:-62 \%$ tot $-37 \%$ ). De mediane duur van dit loopoor was 4 dagen bij de kinderen die waren behandeld met oordruppels, versus 5 dagen bij de kinderen die een antibioticumdrank hadden gekregen $(p<0,001)$ en 12 dagen bij de kinderen bij wie werd afgewacht $(p<0,001)$. De kinderen hadden alleen milde bijwerkingen van de gebruikte medicatie en geen van de ouders rapporteerde complicaties van middenoorontstekingen in de eerste 2 weken.

CONCLUSIE Van de onderzochte behandelingen is behandeling met antibiotica-glucocorticoïdoordruppels het meest effectief bij kinderen met trommelvliesbuisjes die een acuut loopoor ontwikkelen. We adviseren om patiëntinformatie en richtlijnen aan te passen, opdat deze kinderen eerder en met oordruppels worden behandeld.

Julius Centrum voor Gezondheidswetenschappen en Eerstelijns Geneeskunde, UMC Utrecht, Postbus 85060,3508 AB Utrecht: dr. T.M.A. van Dongen, arts-epidemioloog; prof.dr. G.J.M.G. van der Heijden, epidemioloog; dr. R.P. Venekamp, huisarts-in-opleiding, epidemioloog; prof.dr. M.M. Rovers, epidemioloog; prof.dr. A.G.M. Schilder, kno-arts, epidemioloog • Correspondentie: T.M.A.vanDongen@umcutrecht.nl • Mogelijke belangenverstrengeling: het onderzoek is gefinancierd door ZonMw, subsidie 170992502; Nederlands Trial Register, NTR1481.

Dit artikel is een bewerkte vertaling van: Van Dongen TMA, Van der Heijden GJMG, Venekamp RP, Rovers MM, Schilder AGM. A trial of treatment for acute otorrhea in children with tympanostomy tubes. NEJM 2014;370:723-33. Publicatie gebeurt met toestemming van de Massachusetts Medical Society, maar de vertaling is niet door hen beoordeeld.

\section{INLEIDING}

$\mathrm{H}_{\mathrm{u}}^{\mathrm{e}}$ et plaatsen van trommelvliesbuisjes is een van de meest uitgevoerde chirurgische ingrepen bij kinderen. ${ }^{1}$ In het eerste jaar na plaatsing van de buisjes krijgt $67 \%$ van de kinderen een of meer keer een loopoor. ${ }^{2}$ Zo'n loopoor is doorgaans een uiting van otitis media acuta (OMA), waarbij ontstekingsvocht via het buisje de gehoorgang in loopt. Men veronderstelt dat een bacteriële (super)infectie van het middenoor de belangrijkste oorzaak van OMA is, en daarmee ook van een acuut loopoor bij buisjes. ${ }^{3}$ Daarom schrijven artsen vaak orale antibiotica en antibiotica(glucocorticoïd)oordruppels voor. Er zijn echter maar weinig onderzoeken gedaan naar de effectiviteit van deze behandelingen bij een loopoor bij kinderen met trommelvliesbuisjes. De methodologische kwaliteit van de bestaande onderzoeken is matig en/of het aantal deelnemers is klein. ${ }^{4-7}$. Hoe het ook zij, op basis van deze onderzoeken lijken antibioticaoordruppels tenminste gelijkwaardig aan een orale behandeling. ${ }^{5-7}$ Lokale behandeling met antibiotica heeft daarnaast in vergelijking met een orale behandeling het voordeel van een kleinere kans op systemische bijwerkingen en op antibioticaresistentie.,7,8 Omdat OMA ook spontaan over kan gaan, is een afwachtend beleid mogelijk ook een goed alternatief.9,10 De effectiviteit hiervan bij kinderen met een loopoor bij buisjes is echter nog niet eerder onderzocht. We hebben daarom een interventieonderzoek uitgevoerd naar de effectiviteit van de drie meest toegepaste behandelstrategieën bij kinderen met trommelvliesbuisjes die een acuut loopoor ontwikkelen: antibiotica-glucocorticoïdoordruppels, een oraal antibioticum en een afwachtend beleid.

\section{METHODE}

\section{Onderzoeksopzet}

We hebben een gerandomiseerd pragmatisch interventieonderzoek uitgevoerd. Voor een gedetailleerder overzicht van de

\section{Wat is bekend?}

- In het jaar na plaatsing van trommelvliesbuisjes krijgt $67 \%$ van de kinderen een of meer looporen.

- Het staat niet vast welke behandeling het meest effectief is in de acute fase: antibiotica(glucocorticoïd)oordruppels, een oraal antibioticum of een afwachtend beleid.

\section{Wat is nieuw?}

- Behandeling met antibiotica-glucocorticoïdoordruppels is het meest effectief bij kinderen met trommelvliesbuisjes die een acuut loopoor ontwikkelen.

- Afwachten is geen goede behandelstrategie bij een acuut loopoor bij kinderen met buisjes: na twee weken heeft meer dan de helft nog steeds een loopoor en de kans op chroniciteit en recidieven in de maanden erna is groter. 
onderzoeksopzet en gegevensanalyse verwijzen we naar het originele artikel en onderzoeksprotocol op NEJM.org. ${ }^{11}$

\section{Onderzoekspopulatie}

Kinderen van 1 tot 10 jaar oud met trommelvliesbuisjes en een acuut loopoor dat korter dan 7 dagen bestond konden deelnemen aan ons onderzoek. We excludeerden kinderen met koorts (lichaamstemperatuur hoger dan $38,5^{\circ} \mathrm{C}$ ), antibioticumgebruik in de voorgaande 2 weken, plaatsing van trommelvliesbuisjes in de voorgaande 2 weken, een loopoor in de voorgaande 4 weken, 3 of meer episoden in de voorgaande 6 maanden of 3 of meer episoden in het voorgaande jaar.

Van juni 2009 tot en met mei 2012 hebben Nederlandse huisartsen en kno-artsen de ouders van kinderen met trommelvliesbuisjes benaderd voor deelname aan het onderzoek. Ons onderzoeksteam nam telefonisch contact op met ouders die hiervoor interesse hadden. We informeerden ze over het onderzoek en controleerden de in- en exclusiecriteria. Als het kind een loopoor had ten tijde van het telefonisch contact en in aanmerking kwam voor onderzoeksdeelname planden we een huisbezoek door de onderzoeksarts in. Indien het kind geen loopoor had, verzochten we de ouders om contact op te nemen zodra een loopoor ontstond.

Tijdens het huisbezoek gaven ouders schriftelijke toestemming voor onderzoeksdeelname en onderzocht de arts het oor met een otoscoop, nam hij een kweek van het loopoor af voor microbiologische analyse, en verzamelde hij demografische en ziektespecifieke gegevens.

Behandelstrategieën, randomisatie en onderzoeksomvang Aan het eind van het huisbezoek werd het kind door middel van loting (met een 1:1:1-verdeling) ingedeeld in een van drie behandelgroepen: hydrocortison-bacitracine-colistineoordruppels (Bacicoline-B, Daleco Pharma) vijf druppels driemaal daags in het aangedane oor of oren gedurende 7 dagen; amoxicilline-clavulaanzuurdrank 30/7,5 mg per kilogram lichaamsgewicht per dag verdeeld over 3 giften gedurende 7 dagen; of een afwachtend beleid gedurende 2 weken. We hebben de primaire uitkomst gedefinieerd als de aanwezigheid van otorroe bij otoscopie door de onderzoeksarts 2 weken na randomisatie. Uit berekeningen vooraf met een type-2-foutkans van 10\% en een type-1-foutkans van 5\% bleek dat we 105 kinderen in elke behandelgroep nodig hadden om bij een conservatieve primaire uitkomstschatting bij een afwachtend beleid van $60 \% 5,7,12$ een klinisch relevant verschil te vinden voor de primaire uitkomst van ten minste $20 \%$ tussen de groepen. Secundaire uitkomsten waren gebaseerd op door ouders ingevulde dagboekjes en betroffen onder andere de duur van het initiële loopoor, het totaal aantal dagen met een loopoor en aantal recidieven in 6 maanden, en complicaties en bijwerkingen van onderzoeksmedicatie gedurende de eerste 2 weken.

\section{Verzameling en analyse van gegevens}

De ouders hielden gedurende twee weken een dagboek bij over medicatiegebruik, bijwerkingen en complicaties, en gedurende zes maanden over de aanwezigheid van oorklachten. Na twee weken en zes maanden bezocht de onderzoeksarts de kinderen thuis, onderzocht hun oren door middel van otoscopie en nam de dagboekjes in. Als het oor na twee weken nog liep, lieten we de verdere behandeling hiervan over aan de eigen huisarts of kno-arts.

Volgens het intention-to-treatprincipe berekenden wij risicoverschillen met 95\%-betrouwbaarheidsintervallen voor de primaire uitkomstmaat. We maakten kaplan-meiercurves van

Tabel 1 Samenvatting van de meest relevante patiëntkenmerken van de 230 deelnemende kinderen. Een volledig overzicht is te vinden op www.nejm.org.

\begin{tabular}{|c|c|c|c|c|}
\hline Patiëntkenmerk & $\begin{array}{l}\text { Antibioticum-glucocor- } \\
\text { ticoïdoordruppels } \\
(n=76)\end{array}$ & $\begin{array}{l}\text { Orale antibiotica } \\
(n=77)\end{array}$ & $\begin{array}{l}\text { Afwachtend beleid } \\
(n=77)\end{array}$ & $\begin{array}{l}\text { Totaal } \\
(n=230)\end{array}$ \\
\hline Mannelijk geslacht, n (\%) & $50(66)$ & $40(52)$ & $43(56)$ & $133(58)$ \\
\hline $\begin{array}{l}\text { Duur van het loopoor voorafgaand aan inclusie, mediaan } \\
\text { (bereik) }\end{array}$ & $3(0-7)$ & $2(0-7)$ & $2(0-7)$ & $3(0-7)$ \\
\hline Bilateraal loopoor, n (\%) & $14(18)$ & $11(14)$ & $13(17)$ & $38(17)$ \\
\hline Aantal keer dat buisjes zijn geplaatst, mediaan (bereik) & $1(1-7)$ & $1(1-3)$ & $1(1-5)$ & $1(1-7)$ \\
\hline Aantal eerdere looporen, mediaan (bereik) ${ }^{\dagger}$ & $0(0-5)$ & $0(0-5)$ & $0(0-3)$ & $0(0-5)$ \\
\hline \multicolumn{5}{|l|}{ Reden voor huidige buisjes, n (\%) } \\
\hline Recidiverende otitis media acuta & $36(47)$ & $27(35)$ & $36(47)$ & $99(43)$ \\
\hline Chronische otitis media met effusie & $40(53)$ & $50(65)$ & $41(53)$ & $131(57)$ \\
\hline
\end{tabular}

$\mathrm{n}=$ aantal; sd = standaardafwijking.

* inclusief de huidige buisjes.

† bij de huidige buisjes.

We misten gegevens van de duur van het loopoor voorafgaand aan inclusie voor één kind (1\%) uit de orale-antibioticagroep en van het aantal eerdere looporen bij de huidige buisjes voor drie kinderen: één kind (1\%) uit de orale-antibioticagroep en twee (3\%) kinderen die een behandeling kregen met antibioticum-glucocorticoïdoordruppels. We hebben deze gegevens geïmputeerd met de mediaan. 
de duur van het initiële loopoor en gebruikten log-ranktests om de verschillen tussen de groepen uit te drukken. We berekenden de mediaan voor het totaal aantal dagen met een loopoor en het aantal recidieven na zes maanden, en gebruikten mann-whitney-U-tests om de verschillen tussen de groepen te bepalen.

\section{Interim-analyse}

Twee jaar na de start van het onderzoek waren 150 van de geplande 315 kinderen gerandomiseerd. In overleg met ZonMw besloten we een onafhankelijke commissie een (niet van tevoren geplande) interim-analyse uit te laten voeren. Deze commissie was geblindeerd voor de toegewezen behandelingen. Het vooraf gedefinieerd eindpunt was een risicoverschil tussen de groepen groter dan $20 \%$ voor de primaire uitkomst, dat we met een type-1-foutkans kleiner dan $1 \%$ volgens de haybittle-peto-methode hebben getest. Tijdens de interim-analyse gingen we door met het includeren van kinderen. De interimanalyse toonde aan dat het kleinste risicoverschil voor het primaire eindpunt tussen de meest effectieve en de overige behandelingen $-32 \%$ was $(95 \%$ - BI $-48 \%$ tot $-17 \%$, p-waarde < o,oo1). Op 21 mei 2012 adviseerde de commissie om de inclusie

Figuur Kaplan-meiercurve voor de duur van het loopoor na randomisatie, zoals gerapporteerd door de ouders in het dagboek. Zie de volledige publicatie op www.nejm.org voor de bijbehorende aantallen kinderen.

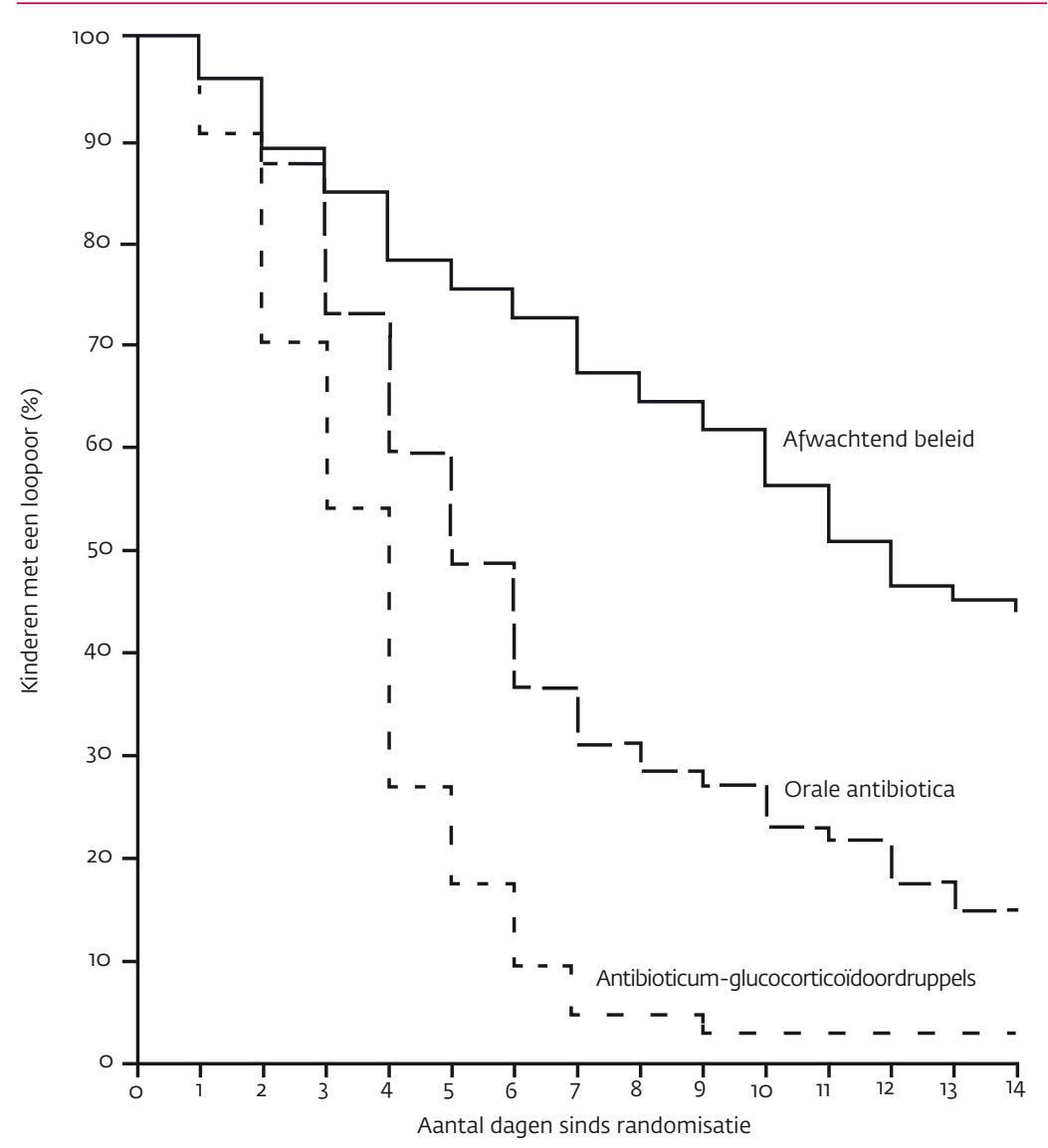

te staken, alle deelnemers volgens protocol te blijven opvolgen en de gegevens geblindeerd te laten analyseren.

\section{RESULTATEN}

\section{Onderzoekspopulatie}

Ouders van 1133 kinderen met trommelvliesbuisjes gaven aan te willen meedoen aan het onderzoek als hun kind een loopoor zou krijgen. Van deze kinderen hebben we er 247 thuis bezocht omdat ouders klachten van een acuut loopoor hadden gemeld; 17 konden niet deelnemen vanwege koorts of omdat het buisje al uitgestoten bleek.

Door middel van loting hebben we 230 kinderen toegewezen aan een van de drie behandelgroepen: antibioticumglucocorticoïdoordruppels ( 76 kinderen), orale antibiotica (77) of een afwachtend beleid (77). Ten tijde van inclusie zagen we geen grote klinisch relevante verschillen tussen de groepen wat betreft demografische en ziektespecifieke kenmerken [tabel 1].

Bij 228 kinderen (99\%) konden we de primaire uitkomst meten en van 221 (96\%) waren dagboeken beschikbaar.

\section{Primaire uitkomst}

De onderzoeksarts zag bij otoscopie 2 weken na start van de behandeling dat $5 \%$ van de kinderen die waren behandeld met antibiotica-glucocorticoïdoordruppels nog otorroe had, versus $44 \%$ van de kinderen die een behandeling kregen met een antibioticumdrank (risicoverschil (RV): $-39 \%, 95 \%-B I-51 \%$ tot $-26 \%$ ) en $55 \%$ van de kinderen bij wie de arts heeft afgewacht (RV: $-49 \%, 95 \%-B I:-62 \%$ tot $-37 \%$ ) [tabel 2].

\section{Secundaire uitkomsten}

De mediane duur van het initiële loopoor was 4 dagen bij kinderen die waren behandeld met antibiotica-glucocorticoidoordruppels versus 5 dagen bij kinderen die waren behandeld met een antibioticumdrank $(\mathrm{p}<\mathrm{o}, \mathrm{oo1})$ en 12 dagen bij kinderen bij wie werd afgewacht $(\mathrm{p}<0,001)$ [tabel 2 en figuur]. Het totaal aantal dagen met een loopoor in 6 maanden (mediaan) was het kleinst in de oordruppelsgroep: 5 dagen versus 13,5 dagen en 18 dagen respectievelijk $(\mathrm{p}<\mathrm{o}, 001)$ [tabel 2]. Het aantal recidieven (mediaan) was ook het kleinst in de oordruppelsgroep [tabel 2]. Geen van de ouders rapporteerde complicaties, zoals lokale cellulitis, mastoïditis en intracraniele complicaties in de eerste 2 weken. Zestien kinderen (21\%) die een behandeling kregen met oordruppels gaven aan pijn te hebben bij toediening en $2(3 \%)$ vertoonden een lokale huiduitslag. Bij 18 kinderen (23\%) die een behandeling kregen met een antibioticumdrank ontstonden er maag-darmklachten en 3 (4\%) ontwikkelden een huiduitslag.

\section{BESCHOUWING}

Ons onderzoek toont aan dat antibiotica-glucocorticoïdoordruppels effectiever zijn dan een oraal antibioticum en een afwachtend beleid bij kinderen met trommelvliesbuisjes die een acuut loopoor ontwikkelen. Onze bevindingen komen overeen met resultaten van de eerdere onderzoeken naar de 


\section{Tabel 2 Resultaten}

\begin{tabular}{|c|c|c|c|c|c|c|}
\hline Uitkomstmaat & $\begin{array}{l}\text { Antibioticum-glucocor- } \\
\text { ticoïdoordruppels } \\
(n=76)\end{array}$ & $\begin{array}{l}\text { Orale } \\
\text { antibiotica } \\
(n=77)\end{array}$ & $\begin{array}{l}\text { Afwachtend } \\
\text { beleid } \\
(n=77)\end{array}$ & $\begin{array}{l}\text { Antibioticum-gluco } \\
\text { versus } \\
\text { afwachtend beleid }\end{array}$ & $\begin{array}{l}\text { orticoïdoordruppels } \\
\text { versus } \\
\text { orale antibiotica }\end{array}$ & $\begin{array}{l}\text { Orale antibiotica } \\
\text { versus } \\
\text { afwachtend beleid }\end{array}$ \\
\hline Otoscopie, $n^{*}$ & 76 & 77 & 75 & & & \\
\hline Loopoor na 2 weken, n (\%) & $4(5)$ & $34(44)$ & $41(55)$ & & & \\
\hline Risicoverschil, \% (95\%-BI) & & & & $-49(-62$ tot -37$)$ & $-39(-51$ tot -26$)$ & $-11(-27$ tot 5$)$ \\
\hline Dagboek, n† & 74 & 74 & 73 & \multicolumn{3}{|c|}{ Verschillen in mediaan $\ddagger$} \\
\hline $\begin{array}{l}\text { Duur van het eerste loopoor, } \\
\text { dagen, mediaan (bereik) }\end{array}$ & $4(1-28)$ & $5(1-36)$ & $12(1-159)$ & $-8(p<0,001)$ & $-1(p<0,001)$ & $-7(p<0,001)$ \\
\hline $\begin{array}{l}\text { Totaal aantal dagen met een } \\
\text { loopoor gedurende } 6 \text { maanden, } \\
\text { mediaan (bereik) }\end{array}$ & $5(1-62)$ & $13,5(1-61)$ & $18(1-159)$ & $-13(p<0,001)$ & $-8,5(p<0,001)$ & $-4,5(p=0,04)$ \\
\hline $\begin{array}{l}\text { Aantal recidieven gedurende } 6 \\
\text { maanden, mediaan (bereik) }\end{array}$ & $0(0-9)$ & $1(0-6)$ & $1(0-5)$ & $-1(p=0,26)$ & $-1(p=0,03)$ & $0(p=0,21)$ \\
\hline
\end{tabular}

* Beoordeeld door onderzoeksarts.

${ }^{\dagger}$ Gerapporteerd door ouders.

‡ Log-ranktest of mann-whitney-U-test.

- Vanaf randomisatie tot de eerste dag met otorroe die wordt gevolgd door 7 of meer dagen zonder otorroe, mediaan van kaplan-meieranalyses.

: $: 1$ of meer dagen met een loopoor na een interval van 7 of meer dagen zonder een loopoor.

effectiviteit van oordruppels en orale antibiotica bij kinderen met trommelvliesbuisjes die een loopoor kregen..$^{-7}$ Een afwachtend beleid is niet eerder onderzocht: wij tonen aan dat dit geen goede behandelstrategie is bij deze kinderen.

We hebben gekozen voor een pragmatische onderzoeksopzet met een robuuste, harde primaire uitkomstmaat en hebben daarom geen blindering toegepast. De otoscopische bevindingen van de onderzoeksarts kwamen niettemin goed overeen met wat de ouders in het dagboek hebben gerapporteerd. Er waren geen verschillen in leeftijd, geslacht en aantal buisjesplaatsingen tussen de deelnemers en de kinderen die wel bij ons werden aangemeld, maar niet aan het onderzoek deelnamen. Door de pragmatische onderzoeksopzet en het feit dat kinderen uit zowel de eerste als de tweede lijn aan ons onderzoek mee konden doen, zijn onze bevindingen breed toepasbaar in de dagelijkse praktijk. ${ }^{13}$

\section{CONCLUSIE}

Behandeling met antibiotica-glucocorticoïdoordruppels is het meest effectief bij kinderen met trommelvliesbuisjes die een acuut loopoor ontwikkelen. We adviseren om patiëntinformatie en richtlijnen aan te passen, opdat deze kinderen eerder en met oordruppels worden behandeld.

\section{DANKWOORD}

Wij danken alle kinderen en hun ouders voor hun enthousiaste deelname; Pauline Winkler, Nelly van Eden, Lidian Izeboud, Dicky Mooiweer en ons team van medisch studenten voor hun praktische en administratieve ondersteuning; de deelnemende huisartsen, in het bijzonder Roger Damoiseaux, Marco Blanker en Herman Kolk, en de kno-artsen van de deelnemende ziekenhuizen; Arno Hoes en Marc Bonten voor hun adviezen tijdens het opzetten van het onderzoek; Marloes van Beurden voor gegevensmanagement; Rolf Groenwold en
Chantal Boonacker voor de assistentie bij de interim-analyse en de leden van de onafhankelijke interim-analysecommissie (Gerard Zielhuis, Hendrik Verschuur en René Eijkemans).

\section{LITERATUUR}

1 Cullen K, Hall M, Golosinskiy A. Ambulatory surgery in the United States, 2006. National health statistics reports, no. 11, revised. Hyattsville, MD: National Center for Health Statistics, 2009.

2 Van Dongen TM, Van der Heijden GJ, Freling HG, Venekamp RP, Schilder AG. Parent-reported otorrhea in children with tympanostomy tubes: incidence and predictors. PLoS One 2013;8:e69062.

3 Peters BM, Jabra-Rizk MA, O'May GA, Costerton JW, Shirtliff ME. Polymicrobial interactions: impact on pathogenesis and human disease. Clin Microbiol Rev 2012; 25:193-213.

4 Vaile L, Williamson T, Waddell A, Taylor G. Interventions for ear discharge associated with grommets (ventilation tubes). Cochrane Database Syst Rev 2006;2:CD001933.

5 Dohar J, Giles W, Roland P, Bikhazi N, Carroll S, Moe R, et al. Topical ciprofloxacin/dexamethasone superior to oral amoxicillin/clavulanic acid in acute otitis media with otorrhea through tympanostomy tubes. Pediatrics 2006;118:e561-e569.

6 Heslop A, Lildholdt T, Gammelgaard N, Ovesen T. Topical ciprofloxacin is superior to topical saline and systemic antibiotics in the treatment of tympanostomy tube otorrhea in children: the results of a randomized clinical trial. Laryngoscope 2010;120:2516-20.

7 Goldblatt EL, Dohar J, Nozza RJ, Nielsen RW, Goldberg T, Sidman JD, et al. Topical ofloxacin versus systemic amoxicillin/clavulanate in purulent otorrhea in children with tympanostomy tubes. Int J Pediatr Otorhinolaryngol 1998;46:91-101.

8 Weber PC, Roland PS, Hannley M, Friedman R, Manolidis S, Matz G, et al. The development of antibiotic resistant organisms with the use of ototopical medications. Otolaryngol Head Neck Surg 2004;130:S89-S94.

9 Rovers MM, Glasziou P, Appelman CL, Burke P, McCormick DP, Damoiseaux RA, et al. Antibiotics for acute otitis media: a meta-analysis with individual patient data. Lancet 2006;368:1429-35.

10 Isaacson G. Why don't those ear drops work for my patients? Pediatrics 2006;118:1252-3.

11 Van Dongen TMA, Van der Heijden GJMG, Venekamp RP, Rovers MM, Schilder AGM. A trial of treatment for acute otorrhea in children with tympanostomy tubes. NEJM 2014;370:723-33.

12 Ruohola A, Heikkinen T, Meurman O, Puhakka T, Lindblad N, Ruuskanen O. Antibiotic treatment of acute otorrhea through tympanostomy tube: randomized double-blind placebo-controlled study with daily follow-up. Pediatrics 2003;111:1061-7.

13 Scott IA, Glasziou PP. Improving the effectiveness of clinical medicine: the need for better science. Med J Aust 2012;196:304-8. 